\title{
Physicochemical and Sensorial Properties of Probiotic Yogurt as Affected by Additions of Different Types of Hydrocolloid
}

\author{
Masoud Bahrami*, Dariush Ahmadi, Mohammad Alizadeh' ${ }^{1}$, and Fakhrisadat Hosseini ${ }^{2}$ \\ Department of Food Science and Technology, Kermanshah Branch, Islamic Azad University, Kermanshah, Iran \\ ${ }^{1}$ Department of Food Science and Technology, Urmia University, Urmia, Iran \\ ${ }^{2}$ Standard Research Institute, Karaj, Iran
}

\begin{abstract}
The main attributes of yogurt that affect consumer satisfaction are taste, consistency, and a firm texture. This study evaluates the influence of xanthan gum, barley beta-glucan, and guar gum in concentrations of $0.05 \%, 0.1 \%, 0.2 \%$, and $0.3 \%$ on probiotic yogurt. The set-type yogurt samples were prepared by using raw cow's milk. The statistical analysis showed that none of these gum additions had any marked effect on $\mathrm{pH}$, titratable acidity, total solids content, and probiotic bacteria counts of yogurt samples. Evaluations for syneresis and water-holding capacity (WHC) in the yogurt samples were affected by the type and concentration of the stabilizer. Yogurts treated with $0.1 \%$ xanthan gum and $0.3 \%$ beta-glucan recorded the highest WHC and the least syneresis. The largest amount of gel firmness was recorded in yogurt samples treated with $0.2 \%$ xanthan gum and $0.3 \%$ beta-glucan. Yogurt samples treated with $0.1 \%$ xanthan gum and $0.3 \%$ beta-glucan were considered acceptable by trained panelists and gained the highest scores in sensory evaluations. The correlation coefficient between the amount of syneresis, WHC and stiffness of texture was significant compared to scores for sensory evaluation $(p<0.01)$. Results for effects of guar gum on the tested parameters were contrary to the results expected from a gum. According to this study, the use of xanthan gum and beta-glucan are highly recommended for low-fat yogurt production.
\end{abstract}

Key words: hydrocolloid, probiotic yogurt, sensorial properties, syneresis

\section{Introduction}

Yogurt is one of the most popular of these dairy-fermented products and is popularly consumed in many societies. Yogurt by itself has been recognized by the medical profession as a healthy food for both adults and children, due to health benefits from high levels of proteins, calcium and vitamins (Sahan et al., 2008).

Probiotic yogurt is a term used to describe any yogurt that contains live, active bacterial cultures. Some of the beneficial effects of consuming probiotic yogurt include: (i) improving intestinal tract health; (ii) boosting the immune system; (iii) reducing symptoms of lactose intolerance; and (iv) reducing the risk of certain cancers (Parvez et al., 2006).

In general, the properties of yogurt are influenced by factors such as the specific chemical composition of the

\footnotetext{
*Corresponding author: Masoud Bahrami, Department of Food Science and Technology, Kermanshah Branch, Islamic Azad University, Kermanshah 6718997551, Iran. Tel: +98-918-8736836, E-mail: bahrami807@yahoo.com
}

milk used in production, the processing conditions and the activity or ability of the starter culture (Mohebbi and Ghoddusi, 2008; Tamime and Robinson, 1999).

The main criteria of yogurt that effects evaluations for quality are its physical properties such as texture, stability and consistency (Zhang et al., 2012). This physical structure of yogurt is largely determined by its protein network. After inoculation of milk with the starter culture, a gradual reduction in $\mathrm{pH}$ occurs that leads to changes in casein micelle aggregations and this result in formation of a cumulative network surrounded by fat and serum globules (Ahmadi, 2010).

Set-type yogurt is commonly consumed in Iran and most consumers prefer yogurt with a firm and rigid texture (Amiri Aghdaei et al., 2010). Variations in viscosity and syneresis are the most common defects in yogurt, especially in low-fat yogurts. Hydrocolloids are sometimes added to milk to prevent occurrence of unfavorable syneresis (Mathias et al., 2011; Tamime and Robinson, 1999).

Hydrocolloids are compounds that can improve the texture of yogurt. These compounds include long and branched molecules, which are able to establish links with each other 
or with other molecules present in the environment in the form of an emulsion. Additions of hydrocolloids to yogurt are effective in absorbing water, increasing viscosity and strengthening and improving the texture of yogurt. Hydrocolloids also safeguard morphological characteristics of yogurt during storage and transportation (Mathias et al., 2011; Mortazavian and Sohrabvandi, 2006).

Several studies have discussed the improvement of physical, textural, flavor and rheological properties of low-fat yogurts by incorporating the stabilizers into the milk. (ElSayed et al., 2002; Paseephol et al., 2008; Sahan et al., 2008; Vasiljevic et al., 2007).

Charles and Carmen (2008) used inulin, guar gum and beta-glucan as fat substitutes. The results showed that amounts of stabilizer had a significant impact on evaluations for texture and syneresis of low-fat fermented skim milk. Similar results were reported for fermented cow's milk with an inulin supplement (Guggisberg et al., 2009).

Adding too much protein and fat will cause excess stiffness of the gel. For example, casein will make yogurt very stiff and granular and/or more evaporation will cause increased acidity, especially during storage. Therefore, it is better to create the desired properties in yogurt by adding stabilizers (Mortazavian and Sohrabvandi, 2006).

This study tested the effects of xanthan gum, barley betaglucan, and guar gum on the physicochemical and sensory properties of probiotic yogurt samples.

\section{Materials and Methods}

\section{Milk}

Raw cow's milk used in this study was obtained from a local dairy processor and processed on the same day. Milk was standardized to a fat level of $1.5 \%$ by blending skim milk and whole milk. Skim milk was prepared by separating raw whole milk using a Westfalia separator (MM 1254, Germany).

\section{Stabilizer}

Xanthan and guar gum were supplied by Poole Co. (England) and food-grade barley beta-glucan was purchased from Pacovis AG Co. (Switzerland).

\section{Preparation of starter cultures}

Yogurt starter containing Lactobacillus delbrueckii ssp. bulgaricus and Streptococcus salivarius ssp. thermophilus (YC-X11) and probiotic bacteria including Lactobacillus acidophilus (LA-5) were supplied from Chr-hansen Co. (Denmark). These cultures are currently used by the dairy industry to produce yogurt. The packages of starter were prepared according to the manufacture's instructions. MRS-bile agar medium (MRS agar: Merck, Germany and bile: Sigma-Aldrich, Inc., USA) was used for the selective enumeration of probiotic bacteria in the presence of yogurt bacteria. Bile was applied at a concentration of $0.15 \%$. The plates were incubated anaerobically at $37^{\circ} \mathrm{C}$ for $3 \mathrm{~d}$ (Sohrabvandi et al., 2012).

\section{Production of yogurt}

The powders of xanthan gum, barley beta-glucan, and guar gum were gradually added separately and directly into a standardized milk base at concentrations of $0.05 \%$, $0.1 \%, 0.2 \%$, and $0.3 \%$. Also, to increase the total solids content, skim milk powder was added to milk $(2 \% \mathrm{w} / \mathrm{v})$. These ingredients were dispersed in milk at $45^{\circ} \mathrm{C}$ for 10 min using a high-speed mixer (L4RT, Silverson Machines Ltd., U.K.) operating at 6,000 rpm. Then the mixtures were homogenized with a Laboratory Homogenizer (Mini-Lab type $8.30 \mathrm{H}$. APV Rannie Co., Denmark) at $60^{\circ} \mathrm{C}$ and a pressure of $20 \mathrm{MPa}$, and were pasteurized at $80^{\circ} \mathrm{C}$ for $30 \mathrm{~min}$ (Lee and Lucey, 2010).

The pasteurized milk was cooled to $42^{\circ} \mathrm{C}$ and inoculated with $2 \%$ commerical starter culture. For production of set-type yogurt, the inoculated milk was distributed into conical plastic cups, ca. $200 \mathrm{~g}$ (height, $80 \mathrm{~mm}$; top dia. $65 \mathrm{~mm}$; bottom dia. $48 \mathrm{~mm}$ ) and sealed with aluminium lids, and incubated at $42^{\circ} \mathrm{C}$. After $2.5 \mathrm{~h}$ of incubation, fermentation was stopped by rapidly cooling. Yogurt samples taken to the refrigerator and were stored at $5^{\circ} \mathrm{C}$.

\section{Chemical analysis}

Total solids content of yogurt samples were determined gravimetrically following AOAC (2000) method 990.20. The $\mathrm{pH}$ values were measured using a digital $\mathrm{pH}-$ meter at $25^{\circ} \mathrm{C}$ which was previously calibrated with $\mathrm{pH} 7.0$ and 4.0 standard buffers. The titratable acidity was determined according the AOAC (2000) titration method 947.05. Acidity was determined by titration with $0.1 \mathrm{~N} \mathrm{NaOH}$ using phenolphthalein as an indicator color. Results were expressed as degree Dornic $\left({ }^{\circ} \mathrm{d}\right)$. Each degree Dornic is equivalent to a decigram of lactic acid per liter.

\section{Syneresis}

Yogurt samples ( $30 \mathrm{~g}$ ) were centrifuged at $222 \mathrm{~g}$ for 10 min at $4^{\circ} \mathrm{C}$ using a centrifuge (30k-300, Sigma Laborzentrifugen $\mathrm{GmbH}$, Germany). After centrifugation, the clear supernatant was poured off, weighed and recorded as percentage of syneresis (Keogh and O'Kennedy, 1998). 


\section{WHC}

According to the method of Parnell-Clunies et al. (1986), a $10 \mathrm{~g}$ sample was centrifuged at 3,000 $\mathrm{g}$ for 30 $\min$ at $4^{\circ} \mathrm{C}$. The supernatant was then removed within 10 min and the wet weight of the pellet was recorded. The WHC was expressed as the percentage of pellet weight relative to the original weight of yogurt.

\section{Gel firmness}

Gel firmness of yogurts were determined at $4-6^{\circ} \mathrm{C}$ by penetration measurements (Texture Analyzer, LFRA-4500, Brookfield, Inc., USA) equipped with a $4.5 \mathrm{~kg}$ load cell. The instrument was adjusted to the following conditions: cylindrical probe (38 $\mathrm{mm}$ in diameter); penetration speed, $1 \mathrm{~mm} / \mathrm{s}$; penetration distance, $30 \mathrm{~mm}$ into surface. The peak force was measured in grams (Kumar and Mishra, 2004; Zhang et al., 2012).

\section{Sensory evaluation}

The Sensory evaluation was carried out by method of El-Sayed et al. (2002). A trained taste panel of ten staff judges evaluated the yogurt samples for flavor (50 points), body and texture (40 points) and appearance (10 points).

\section{Statistical analysis}

The experimental design was a completely randomized design with 1 factor and 12 treatments. All data were analysed using SPSS version 17.0 for Windows (SPSS Inc., USA) with a one-way analysis of variance (ANOVA). Differences between means were compared by Duncan's multiple range tests at a level of 0.05 . The relationships between properties of yogurt were investigated by Pearson's correlation. All experiments were performed in trip- licate.

\section{Results and Discussion}

\section{Total solids content}

The average total solids content of the control yogurt sample was $12.78 \%$ and total solids content of other treatments ranged from $12.77 \%$ to $12.87 \%$ (Table 1 ). It was expected that WHC would increase and syneresis would decrease relative to increased total solid content, but observations shown in Table 1 demonstrate that treatments had no significant difference in terms of amounts of total solids content relative to each other or the control sample.

In other words, additions of any of the tested hydrocolloids had no significant difference in the amount of total solids content in yogurt samples at $p<0.05$. Therefore, the difference in syneresis of the yogurt samples was not related to the total solids content. This observation is in agreement with the results reported by El-Sayed et al. (2002) who that investigated the effect of xanthan gum and different mixes of guar gum, locust bean gum and carboxymethyl-cellulose (CMC).

\section{Acidity and pH}

Table 1 shows that $\mathrm{pH}$ and acidity values were similar for all the yogurt samples. The $\mathrm{pH}$ values ranged from 4.40 to 4.44 , and titratable acidity ranged from 114 to 123 ${ }^{\circ} \mathrm{d}$. Type and concentration of gum had no significant impact on levels of acidity and $\mathrm{pH}$ of the yogurt treatments at $p<0.05$. The same results were obtained by Sahan et al. (2008) with yogurt supplemented with beta-glucan. In addition, Amiri Aghdaei et al. (2010) found that the effect of adding fleawort seed was not significant on the levels

Table 1. Effects of different types of hydrocolloid on physical, chemical and sensory characteristics of yogurt samples

\begin{tabular}{|c|c|c|c|c|c|c|c|c|}
\hline Treatment & $\begin{array}{c}\text { Total Solids } \\
(\%)\end{array}$ & $\begin{array}{l}\text { Acidity } \\
\left({ }^{\circ} \mathrm{d}\right)\end{array}$ & $\mathrm{pH}$ & $\begin{array}{c}\text { Syneresis } \\
(\%)\end{array}$ & $\begin{array}{l}\text { WHC } \\
(\%)\end{array}$ & $\begin{array}{c}\text { Probiotic } \\
\text { bactera count } \\
\left(\times 10^{6} \mathrm{cfu} / \mathrm{g}\right)\end{array}$ & $\begin{array}{c}\text { Firmness } \\
(\mathrm{g})\end{array}$ & $\begin{array}{l}\text { Total } \\
\text { Score }\end{array}$ \\
\hline Control Sample & $12.78^{\mathrm{a}}$ & $116.0^{\mathrm{a}}$ & $4.44^{\mathrm{a}}$ & $46^{\text {cd }}$ & $50.3^{\mathrm{def}}$ & $6.83^{\mathrm{a}}$ & $38.7^{\text {cde }}$ & $80.3^{\text {cde }}$ \\
\hline xanthan gum $0.05 \%$ & $12.84^{\mathrm{a}}$ & $117.3^{\mathrm{a}}$ & $4.42^{\mathrm{a}}$ & $44^{\text {ed }}$ & $56.3^{\mathrm{bc}}$ & $7.90^{\mathrm{a}}$ & $39^{\text {cde }}$ & $83^{\mathrm{cd}}$ \\
\hline xanthan gum $0.1 \%$ & $12.85^{\mathrm{a}}$ & $121.0^{\mathrm{a}}$ & $4.40^{\mathrm{a}}$ & $36.5^{f}$ & $64^{\mathrm{a}}$ & $6.73^{\mathrm{a}}$ & $41^{\mathrm{bc}}$ & $92^{\mathrm{a}}$ \\
\hline xanthan gum $0.2 \%$ & $12.85^{\mathrm{a}}$ & $119.0^{\mathrm{a}}$ & $4.42^{\mathrm{a}}$ & $39.8^{\text {ef }}$ & $58.3^{b}$ & $7.87^{\mathrm{a}}$ & $48^{\mathrm{a}}$ & $85.3^{b c}$ \\
\hline xanthan gum $0.3 \%$ & $12.87^{\mathrm{a}}$ & $118.0^{\mathrm{a}}$ & $4.43^{\mathrm{a}}$ & $41.3^{\mathrm{e}}$ & $58^{\mathrm{b}}$ & $6.60^{\mathrm{a}}$ & $41.17^{\mathrm{bc}}$ & $84.7^{\mathrm{c}}$ \\
\hline beta-glucan $0.05 \%$ & $12.77^{\mathrm{a}}$ & $123.0^{\mathrm{a}}$ & $4.41^{\mathrm{a}}$ & $43.7^{\text {ed }}$ & $50^{\mathrm{ef}}$ & $7.40^{\mathrm{a}}$ & $40.3^{\mathrm{cd}}$ & $80^{\text {cde }}$ \\
\hline beta-glucan $0.1 \%$ & $12.79^{\mathrm{a}}$ & $116.3^{\mathrm{a}}$ & $4.44^{\mathrm{a}}$ & $41.7^{\mathrm{e}}$ & $51^{\text {cde }}$ & $7.73^{\mathrm{a}}$ & $44.17^{b}$ & $81.3^{\text {cde }}$ \\
\hline beta-glucan $0.2 \%$ & $12.78^{\mathrm{a}}$ & $119.7^{\mathrm{a}}$ & $4.43^{\mathrm{a}}$ & $40^{\mathrm{ef}}$ & $55.7 \mathrm{~b}^{\mathrm{cd}}$ & $7.93^{\mathrm{a}}$ & $44.5^{b}$ & $83^{\mathrm{cd}}$ \\
\hline beta-glucan $0.3 \%$ & $12.85^{\mathrm{a}}$ & $116.3^{\mathrm{a}}$ & $4.44^{\mathrm{a}}$ & $36.3^{f}$ & $63.7^{\mathrm{a}}$ & $7.87^{\mathrm{a}}$ & $48.5^{\mathrm{a}}$ & $91^{\mathrm{ab}}$ \\
\hline guar gum $0.05 \%$ & $12.77^{\mathrm{a}}$ & $120.0^{\mathrm{a}}$ & $4.41^{\mathrm{a}}$ & $48.3^{\mathrm{bc}}$ & $45.3^{f}$ & $6.90^{\mathrm{a}}$ & $36.5^{\mathrm{e}}$ & $77.3^{\text {ed }}$ \\
\hline guar gum $0.1 \%$ & $12.81^{\mathrm{a}}$ & $118.3^{\mathrm{a}}$ & $4.40^{\mathrm{a}}$ & $50.7^{\mathrm{b}}$ & $45^{\mathrm{f}}$ & $6.83^{\mathrm{a}}$ & $36.8^{\text {de }}$ & $75.3^{\mathrm{ef}}$ \\
\hline guar gum $0.2 \%$ & $12.80^{\mathrm{a}}$ & $114.0^{\mathrm{a}}$ & $4.44^{\mathrm{a}}$ & $55.7^{\mathrm{a}}$ & $39.7^{\mathrm{g}}$ & $7.87^{\mathrm{a}}$ & $32.7^{\mathrm{f}}$ & $69.7^{\mathrm{fg}}$ \\
\hline guar gum $0.3 \%$ & $12.83^{\mathrm{a}}$ & $117.7^{\mathrm{a}}$ & $4.43^{\mathrm{a}}$ & $56 .^{a}$ & $39^{g}$ & $7.67^{\mathrm{a}}$ & $32.17^{\mathrm{f}}$ & $68.7^{\mathrm{g}}$ \\
\hline
\end{tabular}

Within the same column, the values with the different letter are significantly different $(p<0.05)$. 
of $\mathrm{pH}$ and acidity of low-fat yogurt.

\section{Syneresis}

Syneresis is one of the basic defects of yogurt, which is observed in the form of accumulation of serum or whey on yogurt surface. Syneresis occurs due to shrinkage of the three-dimensional (3D) structure of a protein network, which leads to the reduction of connection power of whey proteins and its exit from the yogurt.

There was significant difference between syneresis of tested treatments $(p<0.05)$. The least amount of syneresis was observed in yogurts containing $0.1 \%$ xanthan gum and $0.3 \%$ beta-glucan, while the largest amount of syneresis was observed in yogurt samples containing $0.3 \%$ guar gum (Fig. 1).

Syneresis decreased with an increased concentration of beta-glucan gum because of its role in the formation of a denser gel network in comparison with the control sample and its ability to absorb water. With regards to the xanthan gum, syneresis decreased with an increased concentration of up to $0.2 \%$, but then syneresis of the yogurt samples increased.

Keogh and O'Kennedy (1998) examined the effect of gelatin, wheat starch and a mixture of locust bean gum and beta-glucan on the syneresis of stirred yogurt. Starch had no significant effect, but the effects of gelatin and the mixture of locust bean gum and beta-glucan were significant. In a similar study, Sahan et al. (2008) found that syneresis in yogurt decreased with an increased mix of locust bean gum and beta-glucan by as much as $0.16 \%$ and syneresis in yogurt increased in concentrations higher than that.

According to the parameters used to evaluate yogurt in these tests, the effects of adding guar gum were contrary to expectations. The addition of guar gum significantly $(p<0.05)$ increased the syneresis of yogurt samples. The reason for this may be related to the optimal $\mathrm{pH}$ differ-

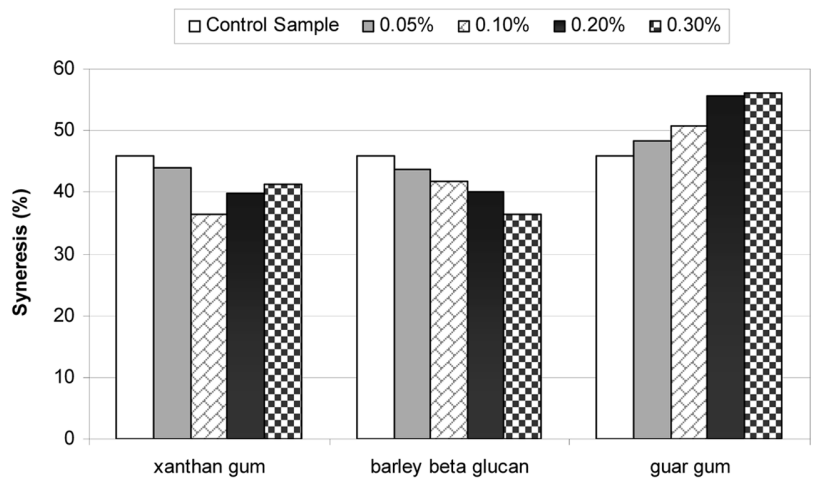

Fig. 1. The syneresis of yogurts as affected by different stabilizers at varying concentrations. ence of the activity of guar gum (7.5-9) with yogurt $\mathrm{pH}$ (4.5-4.7). This result contradicts the results of another related research study by Charles and Carmen (2008) who reported that guar gum decreased syneresis in yogurt.

\section{Water Holding Capacity}

Evaluations for WHC showed significant difference between the yogurt treatments $(p<0.05)$. The highest WHC was recorded for the yogurt with $0.1 \%$ xanthan gum and $0.3 \%$ beta-glucan and the least amount for WHC was recorded for yogurt containing $0.3 \%$ guar gum (Fig. 2). An addition of xanthan gum at a concentration over $0.1 \%$ decreased WHC. Table 2 shows that the correlation coefficient between syneresis and WHC was equal to -0.883 with a significant difference $(p<0.01)$. The results of this study were consistent with the results reported by Sahan et al. (2008) upon addition of beta-glucan gum to the yogurt.

WHC in samples containing $0.1 \%$ of guar gum had significant difference $(p<0.05)$ compared to the control sample. With an increased concentration of guar gum, there was an incremental reduction of WHC, so that the minimum WHC was observed in the sample containing $0.3 \%$ guar gum.

Hydrocolloids caused a reduction of syneresis in yogurt and increased WHC in two ways physical and chemical. Free water is physically trapped and confined within the increased network density, and chemically, the hydrophilic nature of hydrocolloids facilitates a link with the water molecules as, thus increasing gel water-binding capacity (WBC).

\section{Probiotic bacteria counts}

Probiotic yogurt is a classic example of a functional food. Special types of yogurts are often manufactured for dietetic and/or therapeutic purposes and are known as bioyogurts (Parvez et al., 2006). The primary probiotic bacteria associated with dairy products are Lactobacillus acidophilus, Lactobacillus casei and Bifidobacteria which were

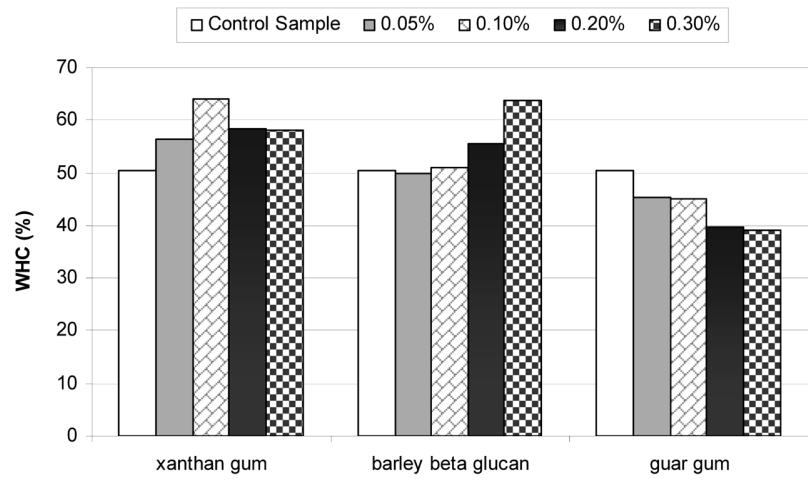

Fig. 2. The WHC of yogurts as affected by different stabilizers at varying concentrations. 
Table 2. Pearson's correlation coefficients between some of properties of yogurt samples

\begin{tabular}{|c|c|c|c|c|c|c|c|c|}
\hline Factor & $\begin{array}{l}\text { Total } \\
\text { Solids }\end{array}$ & Acidity & $\mathrm{pH}$ & Syneresis & WHC & $\begin{array}{c}\text { Probiotic } \\
\text { bactera count }\end{array}$ & Firmness & $\begin{array}{l}\text { Total } \\
\text { Score }\end{array}$ \\
\hline Total Solids & 1 & & & & & & & \\
\hline Acidity & .093 & 1 & & & & & & \\
\hline $\mathrm{pH}$ & .056 & $-.530 * *$ & 1 & & & & & \\
\hline Syneresis & -.169 & -.261 & .168 & 1 & & & & \\
\hline WHC & .199 & .201 & -.109 & $-.883 * *$ & 1 & & & \\
\hline Probiotic bactera count & .097 & -.125 & $.347 *$ & -.029 & -.033 & 1 & & \\
\hline Firmness & .078 & .099 & .100 & $-.820 * *$ & $.751 * *$ & .222 & 1 & \\
\hline Total Score & .198 & .104 & -.155 & $-.875 * *$ & $.885 * *$ & -.126 & $.720 * *$ & 1 \\
\hline
\end{tabular}

$*$ and $* *$ Correlation is significant at the $(p<0.05)$ and $(p<0.01)$ level, respectively.

included in the group of lactic acid bacteria but not all lactic acid bacteria is probiotic.

In order to provide certain health benefits to humans, the count of probiotic bacteria in fermented milk should be $10^{6}$ colony forming units (CFU)/g at the end of the shelflife of a product (Ahmadi, 2010; Sanders and Huis in't Veld, 1999). It seems reasonable to assume that the beneficial effects of probiotic bacteria can be expected only when viable cells are ingested.

In this study, although there was no significant $(p<0.05)$ difference between cell numbers of probiotic bacteria in the samples, all treatments had more probiotic bacteria than the minimum requirement (Table1).

The results of this study are consistent with the study by El-Sayed et al. (2002). That study determined that adding xanthan gum and mixes of different amounts of guar gum, CMC and locust bean gum did not affect amounts of probiotic bacteria.

\section{Firmness of texture}

Texture characteristics are important criteria for evaluating the quality of yogurt. As can be observed from Table 1 , there was a significant difference in texture between the treatments $(p<0.05)$. That is to say that the effect of adding xanthan gum, beta-glucan and, guar gum on firmness of texture of yogurt samples was significant. The addition of betaglucan significantly increased firmness of the yogurt, so that the maximum firmness was observed upon addition of $0.2 \%$ xanthan gum and $0.3 \%$ beta-glucan (Fig. 3 ).

Evaluations for stiffness of yogurt samples determined that stiffness reduced with increased concentrations of guar gum, so that the minimum stiffness was observed in yogurt containing $0.3 \%$ of guar gum. The sample yogurt containing $0.05 \%$ of xanthan gum had no significant difference with the control sample, but evaluations for stiffness of the yogurt increased with increasing amounts of gum. The correlation coefficient of stiffness of the samples was significant $(p<0.01)$ with the level of syneresis and WHC by as much as -0.820 and 0.751 , respectively.

Gums either create gel themselves or produce a network of connections between components of the casein network. Therefore, gums also increase the strength and stiffness of the texture of a yogurt gel. Gums can increase the strength of the yogurt gel by increasing the WBC indicator. Properties of solidity and elasticity of gel were increased with an increased WBC.

\section{Sensory evaluation}

Sensory evaluations showed significant difference between the yogurt samples $(p<0.05)$. The highest score was obsorbed in samples containing $0.1 \%$ xanthan gum and $0.3 \%$ beta-glucan, with levels of 92 and 91 , respectively. The lowest score was 68.7, and was observed in the sample containing $0.3 \%$ guar gum (Fig. 4). As shown in Table 2 the correlation coefficient between the amount of syneresis, WHC and stiffness of texture was significant compared to scores for sensory evaluation $(p<0.01)$. The yogurt sample containing $0.05 \%$ guar gum had significant difference with the control sample in the sensory evaluation. Results showed that with an increasing amount of guar gum, the sensory score of the yogurt treatments decreased.

Charles and Carmen (2008) used beta-glucan and inulin as fat substitutes. Then, yogurt syneresis reduced and rheo-

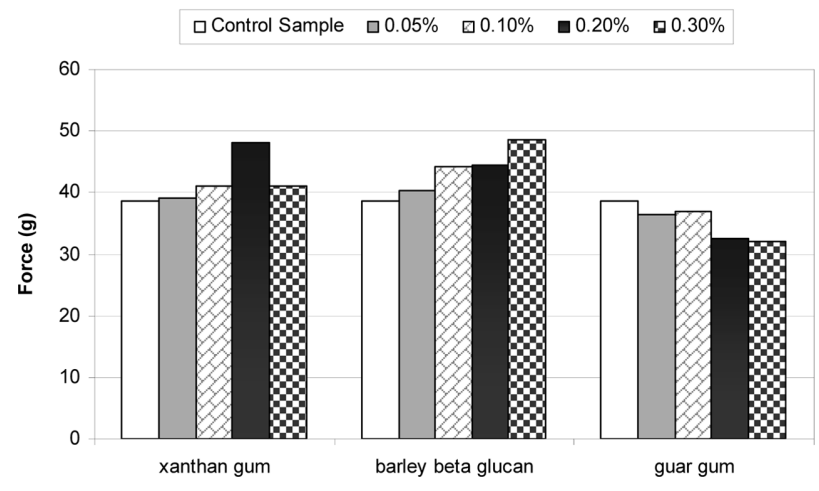

Fig. 3. The firmness of yogurts as affected by different stabilizers at varying concentrations. 


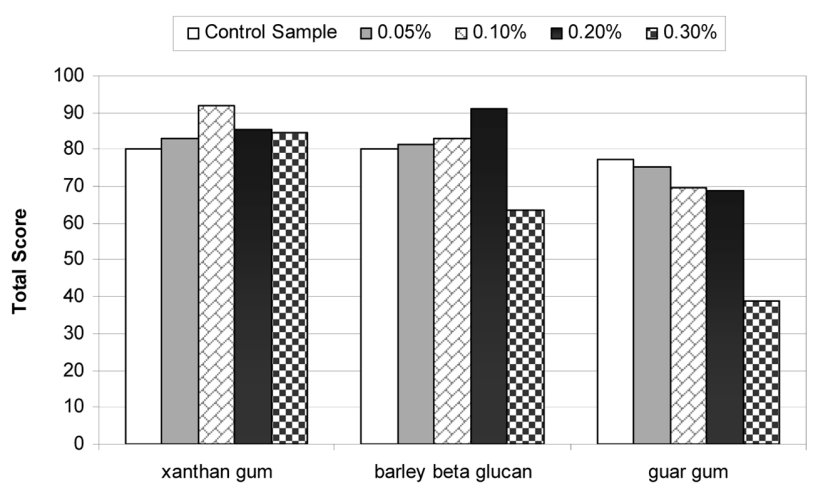

Fig. 4. The sensory evaluation of yogurts as affected by different stabilizers at varying concentrations.

logical and textural characteristics of the yogurt noticeably improved. The texture of yogurt improved with addition of $0.05 \%$ beta-glucan, but a concentration of more than $2 \%$ was required in order to actualize the effect of beta-glucan and inulin.

\section{Conclusions}

The results of this study showed that none of the tested gums had a significant effect on $\mathrm{pH}$, titratable acidity, total solids content, and probiotic bacteria counts of yogurt samples, but gums were effective on syneresis, WHC, stiffness of texture, and sensory characteristics of the yogurt samples.

According to evaluations of the juries, the best results were obtained by adding $0.1 \%$ concentration of xanthan gum and $0.3 \%$ beta-glucan. Since additions of xanthan gum and beta-glucan improved the texture and reduced syneresis of the samples compared to the control sample, the use of xanthan gum and beta-glucan are highly recommended for low-fat yogurt production.

\section{References}

1. Ahmadi, D. (2010) Optimization of production probiotic yogurt by artificial neural network. M.Sc. thesis, Urmia Univ., Urmia, Iran (in Persian).

2. Amiri Aghdaei, S. S., Aelami, M., and Rezaei, R. (2010) Influence of fleawort seed hydrocolloid on physicochemical and sensory characteristics of low-fat yogurt. Iran. Food Sci. Technol. Res. J. 6, 201-209 (in Persian).

3. AOAC. (2000) Official methods of analysis. 17th ed, Association of Official Analytical Chemists, Washington, DC, USA.

4. Charles, S. B. and Carmen, M. T. (2008) Carbohydrate-based fat replacers in the modification of the rheological, textural and sensory quality of yogurt: Comparative study of the utilization of barley beta-glucan, guar gum and inulin. Int. J. Food Sci. Technol. 43, 824-833.

5. El-Sayed, E. M., Abd El-Gawad, I. A., Murad, H. A., and Sa- lah, S. H. (2002) Utilization of laboratory-produced xanthan gum in the manufacture of yogurt and soy yogurt. Eur. Food Res. Technol. 215, 298-304.

6. Guggisberg, D., Cuthbert-Steven, J., Piccinali, P., Butikofor, U., and Eeberhand, P. (2009) Rheological, microstructural and sensory characterization of low-fat and whole milk set yogurt as influenced by inullin addition. Int. Dairy J. 19, 107-115.

7. Keogh, M. K. and O'Kennedy, B. T. (1998) Rheology of stirred yogurt as affected by added milk fat, protein and hydrocolloids. J. Food Sci. 63, 108-112.

8. Kumar, P. and Mishra, H. N. (2004) Mango soy fortified set yoghurt: Effect of stabilizer addition on physicochemical, sensory and textural properties. Food Chem. 87, 501-507.

9. Lee, W. J. and Lucey, J. A. (2010) Formation and physical properties of yogurt. Asian-Aust. J. Anim. Sci. 23, 1127-1136.

10. Mathias, T. R. S., Carvalho Junior, I. C., Carvalho, C. W. P., and Servulo, E. F. (2011) Rheological characterization of coffee-flavored yogurt with different types of thickener. Alim. Nutr. 22, 521-529.

11. Mohebbi, M. and Ghoddusi, H. B. (2008) Rheological and sensory evaluation of yogurts containing probiotic cultures. $J$. Agric. Sci. Technol. 10, 147-155.

12. Mortazavian, A. M. and Sohrabvandi, S. (2006) Probiotics and food probiotic products. Eta Press, Tehran, pp. 31-69 (in Persian).

13. Parnell-Clunies, E. M., Kakuda, Y., and Deman, J. M. (1986) Influence of heat treatment of milk on the flow properties of yoghurt. J. Food Sci. 51, 1459-1462.

14. Parvez, S., Malik, K. A., Kang, Ah. S., and Kim, H. Y. (2006) Probiotics and their fermented food products are beneficial for health. J. Appl. Microbiol. 100, 1171-1185.

15. Paseephol, T., Small, D., and Sherkt, F. (2008) Rheology and texture of set yogurt as affected by inulin addition. J. Texture Stud. 39, 617-634.

16. Sahan, N., Yasar, K., and Hayaloglu, A. A. (2008) Physical, chemical and flavour quality of non-fat yogurt as affected by a $\beta$-glucan hydrocolloidal composite during storage. Food Hydrocolloid. 22, 1291-1297.

17. Sanders, M. E. and Huis in't Veld, J. (1999) Bringing a probiotic-containing functional food to the market: Microbiological, product, regulatory and labeling issues. Anton. Leeuw. Int. J. G. 76, 293-315.

18. Sohrabvandi, S., Mortazavian, A. M., Dolatkhahnejad, M. R., and Bahadori Monfared, A. (2012) Suitability of MRS-bile agar for the selective enumeration of mixed probiotic bacteria in presence of mesophilic lactic acid cultures and yoghurt bacteria. Iran. J. Biotechnol. 10, 16-21.

19. Tamime, A. Y. and Robinson, R. K. (1999) Yogurt science and technology. 2th ed, CRC Press, Boca Raton F. L., NY, pp. 5090.

20. Vasiljevic, T., Kealy, T., and Mishra, V. K. (2007) Effects of beta-glucan addition to a probiotic containing yogurt. J. Food Sci. 72, 405-411.

21. Zhang, T., Zhang, Z., Yan, H., Li, D., Yang, Z., and Guo, M. (2012) Effects of stabilizers and exopolysaccharides on physiochemical properties of fermented skim milk by Streptococcus thermophilus ST1. Afr. J. Biotechnol. 11, 6123-6130.

(Received 2013.1.8/Revised 2013.4.24/Accepted 2013.6.13) 